\title{
On Semiotic Features of Post-modernistic Visual Poetry in Advertisement
}

\author{
Yanni Li, Shixing Li, Liu Likun, Wang Peiguo, Yiqun Liu, Baichao Gong \\ School of Foreign Languages, Changchun Institute of Technology, Jilin 130012, China; \\ aliyanni2007@163.com
}

Keywords: advertisement; post-modernism; visual poetry; semiotics

\begin{abstract}
As the popularization of science and technology, similar techniques are applied into manufacturing, leading to a lack of individuality and creativity in commodities. Owing to post-modernistic trend of thought, consumer psychology focuses on the individuality of commodity; however, those from mass production can not meet consumer's psychological demand. As an important channel of commercial information for the public, advertisement plays an irreplaceable role in sales promotion. And actually, advertisement speaks for commodity. Under post-modernistic trend of thoughts, this paper uses Charles Sanders Peirce's semiotics as its theory, and applies the semiotic feature of post-modernistic visual poetry to current advertisement, which can keep pace with the changing consumer psychology and social state. From this subject, this paper gives a more precise and concrete orientation to advertisement.
\end{abstract}

\section{Introduction}

Owing to post-modernism, a prevailing trend of thought in modern society, people's value and thinking pattern have changed dramatically. Its influence on consumers' psychology appears as a strong demand for individuality and creativity. However, for the popularization of science and technology, manufacturing adopts technically similar process, leading to the "identity" of commodities. It's harder and harder for manufacturers to produce individualized products. Eventually, the barrier on sales shows up.

As an essential link in sales, advertisement is oriented and designed for meeting consumer's demand and psychological preference with the aim of promoting sales. Since it conveys commercial information and represents commodities symbolically, the lack of commodities can be complemented by individualizing advertisement. So far as that is concerned, how to improve advertisement to cater for the consumer's demand comes into question.

As for the research on modern advertisement, many scholars suggest their opinions connecting with consumer psychology, advertising language, cross-culture advertising and marketing, and also including a part of research on the design of advertisement in relation with semiotics.

However, what proposed here is to connect the visual design of advertisement with the features of post-modernistic visual poetry on the basis of Pierce's semiotics. As a medium of explaining, semiotics serves as a tie between advertisement and visual poetry on their common semiotic features. This provides the foundation for the application of visual poetry to advertisement.

\section{Features of post-modernistic poetry}

Firstly its literary features make up the basic meanings of the poetry. Usually, people understand post-modernistic poetry in two groups: one group suggests that it is a school of poetry since 1950s in the west or even the world; the other group argues that all poetries after modernism are post-modernistic poetry. Although it is a school of poetry, post-modernistic poetry lacks of definite creed and strict system as well as a group of people who share the same or similar interest and composition tendency[1].

The mainstreams of post-modernistic poetry include the Beat, the Black Mountain, the Confession, the New York, and so on. The basic characters of the post-modernist poetry may be summarized as 
follows: Central clear-up and meaning suspense; Planed, scattered and illogical; Putting together and reconstruction of anti-satire; Creation of extempore and long performance; Language recreation and experiment; The heartfelt emotion to the Orient Culture, especially the Chinese Culture[2].

Apart from the literary features above, another striking point shall be mentioned as main point, that is, the designed form, or shape of post-modernistic poetry. Holding the basic spirits of post-modernism, post-modernistic poetry reflects itself expressly unconventional or illogical. The text of poem has been fragmented and composed casually as poets' will. Shape of poem is designed as the shape of the image in poem, or a special form to strengthen and intensified the theme of poem. This kind of specially designed poetry is called "visual poetry", or "concrete poetry", or "concrete-visual poetry", which presents the word arrangement to be visual image and strikes the reader with underlying content. A visual poetry is much more like a picture conveying aesthetic meaning.

. Take the following two visual poems as examples.

"Dove's Song," by Court Smith, Anthropology and Humanism Quarterly, 1996: 27.

(1) In the first poem, the image of a dove is protruded to be the most striking element. Written in normal order, the content of this poem can be recognized as follows:

"Cast away your arms, Dress for peace, Wrap in nature’s cloak."

It is easily found that there is no subject, and in spite of the image that letters forming, the audience could hardly perceive the theme. If there were no image, this work can also hardly be called as a poem for its simple languages with nearly no features of a poem. However, in post-modernism, with the features of central clear-up and meaning suspense, the image of dove formed by letters turns out to be the only theme of this poem, which associates with all the meanings. Then we can rearrange the letters in lines in the order of time conventionally, thus put this poem in this way:

"Dove, cast away your arms,Dress for peace, Wrap in nature’s cloak."
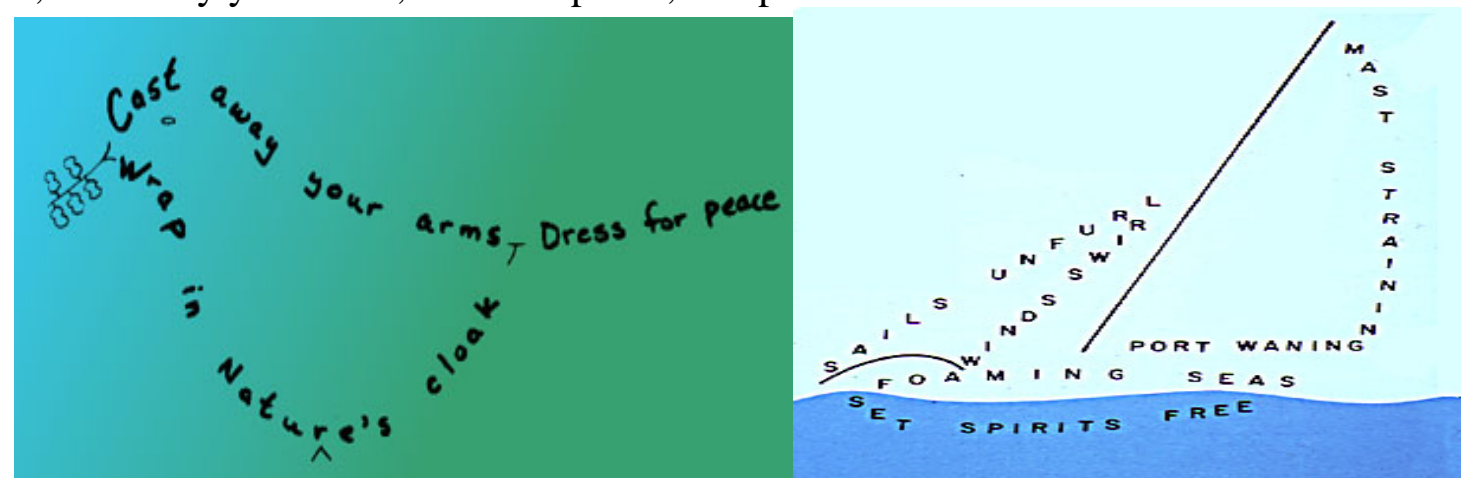

At this moment, the poem gets a complete structure of linguistics but still without full sense of aesthetics. Take a look back at the original poem, why the former is impressive while the latter is plane and dull, and why the contrast is so trenchant between the two?

Holding this question, let's move on to the next poem created by the same poet.

"Breezes” by Court Smith. The Windless Orchard, 1995: 68. (http : // oregonstate . edu / instruct /anth /smith /concr poe .htm . 2007, 5, June. 21:25)

(2) Putting aside the central image of a sailing boat, rearranging letters in line in the order of time, The second poem can be rewritten in this way:

"Sails unfurl, winds swirl, Mast straining, port waning,

Foaming seas set spirits free.”

Similar as this poem , the audience can only gain a vague meaning from literal presentation that the poet is describing a sailing boat. Nevertheless, the image that the original poem presents to us is visual and direct, which form a contrast with the literal presentation.

Now, the questions mentioned previously in the first poem can be answered now. What makes the original poem so distinct, comprehensible and impressive? It's not difficult for anyone to find the reason. Absolutely, the shape of this poem is where the shoe pinches. With the image, although without the literal subject, the original one gives a striking impression to readers. Getting rid of the conventional form of poetry and arranging the letters in a visual way, the audience even actually gain 
a more comprehensible understanding than from the pure literal presentation[3]. And that is the distinctively formal features of post-modernistic visual poetry.

A visual poetry is one that takes the shape of the object it describes, in other word, visual poetry has no theme but in the shape of the poem. And that is the outstanding difference making it distinct out of others.Although people can tell the advantages of visual poetry from contrasting and analyzing cases, to prove this argument valid and reasonable, the efficient way is to take the approach of theory. And then, it will be proved out by theoretical support of semiotics.

\section{Semiotic Features of Post-modernistic Visual Poetry in Advertisement}

Poetry reflects the spirit of society. As a way of expressing, poetry reveals, conveys and interprets people's emotion. And advertising is no longer used merely aiming at promotion and pushing sales; however, people endow advertising with more significance as a tool of popularizing information and leading tide of fashion.

In advertisement, iconic and indexical signs compose images, and symbols are presented as words. Images and words are both essential elements of advertisement. Although some advertisements are composed in literal form like handbills, it does not prove advertisement can success without images. Actually, some kinds of information can hardly interpreted only by words. An advertisement with both images and words can not only present the product directly and vividly, but also express extra meanings that neither of the single one, in order to gain the best advertising affect.

In visual advertisement, images exert emotional impact on audience. Sometimes images draw people's desire to read the words, and in turn, words are explained by images. In an advertisement composed with both images and text, effects are pushed to the audience from different aspects simultaneously.

In the following advertisement (1), we can find all of the three categories of signs combined in this little picture. A figure of traditional Chinese painting represents iconic sign, scenery of buildings peers from behind the indistinct stain of ink, which presents as indexical signs implying a project of a real estate, and several Chinese characters, representing symbolic signs, are arranged on the left side of whole picture in traditional Chinese orders. Firstly, this advertisement gives people an aesthetic enjoyment owing to the contribution of Chinese painting (iconic sign). With its lively air of Chinese tradition, people can easily associate the product with traditional Chinese culture. Then, with the move down along the branch of club, buildings unveil from the drop of ink, indicating people that the product is about a set of real estate. So far, the audience has gained a brief outlook of the product; however, to add more information, the Chinese characters by the left side make the proper effect. In Chinese culture, the plum blossoms represent an outstanding and superb personality or achievement. Here it symbolizes the project as a superb work of realty industry. This is just the perfect effect of the combination of three categories. Each sign plays its own trick and meanwhile helps the others.

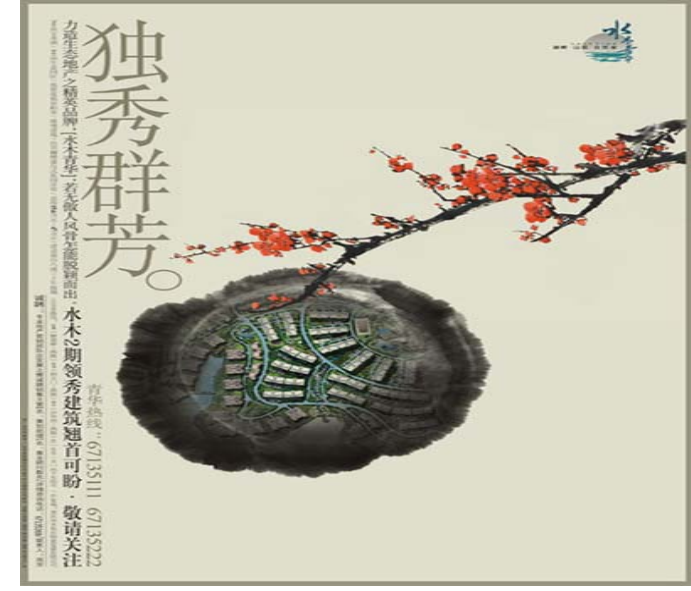

(1) an advertisement for real estate

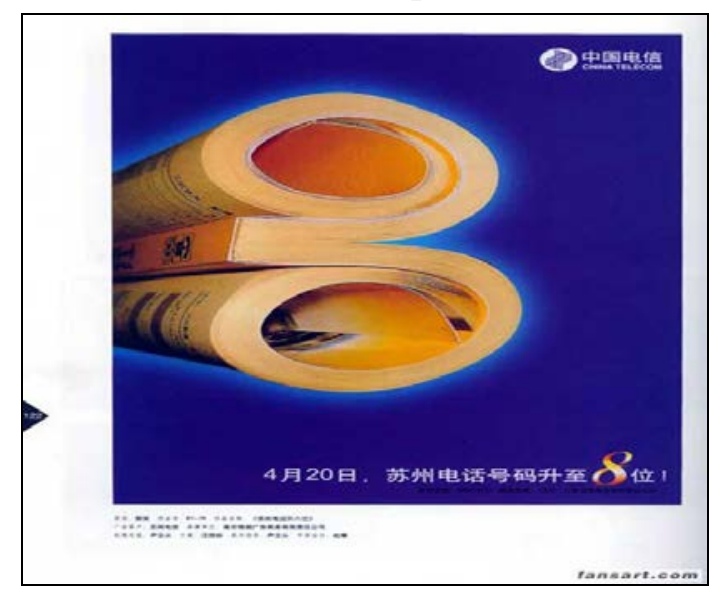

(2) an advertisement for the telecommunication

Advertisement (2) is another good example for signs' combination. The most striking figure is a number " 8 ". When you take a closer look you can find the number is formed by a rolled-up book. 
People can find a reasonable explanation of this combination. The advertisement is for Su Zhou, which is an old scenic city with great historical significance and cultural air. While in Chinese, number " 8 " is traditionally regarded as a symbol of "getting rich". For a famous city with wealth of culture, people are not willing to relate " 8 " with earthly money, but book which indicating culture can fix this contradiction right to the point. Obviously, people in Su Zhou prefer presenting themselves as the image of wealth of culture rather than that of money.

Letters of website address form a tie connecting the two half of the world. What's more interesting is that the tie is a sign of infinite in mathematics. Cooperating with words, images formed by letters arouse people association, matching its theme of "from connecting to the infinite" [4]. Indexical signs (address of website) and iconic signs (map of world), as well as symbolic signs (tie and Chinese characters) have formed a combination.

\section{Summary}

Semiotics serves as a tie in analyzing advertisement and post-modernistic visual poetry[5]. To make proper improvement in advertisement, people should value the arrangement and combine the three categories of signs.

Under the background of post-modernism, consumer psychology is featured as self-concept, desiring for otherness. As symbol of commodities, advertisement must promote products in an individualized way. Of course, advertisement is no longer a purely literal handbill or a poster with simple picture, instead, advertisement is now on its way to diversification and individualization. People are not satisfied with identified commodities, in which advertisement must hold some individuality in place of real materials.

In semiotics, the formal features of post-modernistic visual poetry are the combination of iconic, indexical and symbolic signs, which is the reason why visual poetry strikes its audience so impressively. Through semiotic features of advertisement analyzed in the previous part, it is possible to apply them to the visual design of advertisement on the basis of common features of both visual poetry and advertisement in semiotics, resulting in individualizing advertisement, impressing consumers and exciting consumer psychology.

By successfully relating visual poetry with advertisement, it is proved that post-modernistic visual poetry has the advantage of presentation with both words and images, which can be explained as its semiotic feature of the combination of iconic and symbolic signs, in total match with the visual design of modern advertisement.

\section{Acknowledgements}

The authors would like to give their thanks to The Education Department of Jilin Province (NO. 2015-201) and National Program of Business Startups for University Students (2015-31; 2015-32) for their financial and technical support.

\section{References}

[1]. Joanna Thornborrow \& Shân Wareing. Patterns in language: Stylistics for Students of Language and Literature. Beijing: Foreign Language Teaching and Research Press, 2000, p172-175.

[2]. Zeng Yanbing. Features and Sources of Post- modernism Poetry in Western World. Journal of Shanxi University, 2000(5), p 10-14.

[3]. Li Yanni, Li Jiayin, Lv Zheng, Li Tianyu and Tang Yanling. Study of Online Accounts Safety and Online Payments by Smart Phones. Journal of Software Engineering, 2015 9(4), p877-885

[4]. Li Yan. On Cognitive Function of Metaphor. Journal of Harbin College, 2006, 8: 99-101.

[5]. Jay Parini \& Brett C. Millier. The Columbia History of American Poetry. Beijing: Foreign Language Teaching and Research Press, 2005. 